\title{
RESISTÊNCIA A COMPRESSÃO DE TIJOLOS DE SOLO-CIMENTO FABRICADOS COM O MONTÍCULO DO CUPIM Cornitermes cumulans (Kollar, 1832)
}

\author{
Resistance the compression of manufactured cement bricks ground with the wooded hill \\ of termite Cornitermes cumulans (Kollar, 1832)
}

\author{
Leandro Queiroz Corrêa de Albuquerque ${ }^{1}$, Guilherme Augusto Biscaro ${ }^{2}$, Sérgio Ricardo Lima Negro ${ }^{3}$, \\ Alessandra Conceição de Oliveira ${ }^{4}$, Laércio Alves de Carvalho ${ }^{5}$, Stella Tosta Leal ${ }^{6}$
}

\begin{abstract}
RESUMO
Objetivou-se neste trabalho, comparar a resistência à compressão de tijolos de solo-cimento fabricados com o montículo do cupim Cornitermes cumulans (Kollar, 1832), com tijolos que utilizaram como matéria prima um NEOSSOLO QUARTZARÊNICO (EMBRAPA, 1999), ambos submetidos a duas idades de cura (07 ou 28 dias). O experimento foi montado em delineamento inteiramente casualizado, em esquema fatorial $2 \times 2$, sendo analisados dois cofatores: a matéria prima base e a idade de cura. Os ensaios físicos e mecânicos obedeceram às prescrições das normas da Associação Brasileira de Normas Técnicas NBR-8492 (ABNT, 1982) e NBR-8491 (ABNT, 1984). Concluiu-se que a resistência à compressão dos tijolos foi maior com o aumento das idades de cura. O tratamento T4 apresentou maior valor de resistência à compressão, não diferindo estatisticamente dos tratamentos T2 e T1. Os tijolos fabricados com o montículo do cupim $C$. cumulans (Kollar, 1832) apresentaram diminuição da absorção de água com o aumento das idades de cura, o que normalmente corresponde a um maior aumento da resistência à compressão, ao contrário dos que utilizaram o NEOSSOLO QUARTZARÊNICO (EMBRAPA, 1999).
\end{abstract}

Termos para indexação: Idade de cura, ensaios físicos e mecânicos, solo-cimento.

\section{ABSTRACT}

The aim of this research was to compare the compressive strength of ground-cement bricks manufactured with the wooded hill of termite Cornitermes cumulans (Kollar, 1832), to bricks that they were used as quartzaremico raw material one NEOSSOLO QUARTZARÊNICO (EMBRAPA, 1999), both submitted to two ages of cure (07 or 28 days). The experiment was performed in entirely randomized delineation, in factorial project $2 \times 2$, being analyzed two cofactors: the raw material base and age of cure. The physical and mechanical assays obeyed the lapsing of the norm of the Brazilian Association of Technical Rules NBR-8492 (ABNT, 1982) and NBR-8491 (ABNT, 1984). One concluded that the compressive strength of the bricks was bigger with the increase of the ages of cure. The T4 treatment presented bigger value of compressive strength, not differing statistically from the treatments $\mathrm{T} 2$ and T1. The bricks manufactured with the wooded hill of termite C. cumulans (Kollar, 1832) presented reduction of water absorption with the increase of the ages of cure, which normally corresponds to a bigger increase of the compressive strength, on the contrary of the ones that used NEOSSOLO QUARTZARÊNICO (EMBRAPA, 1999).

Index terms: Ages of cure, physical and mechanical assays, cement-soil.

(Recebido em 21 de setembro de 2006 e aprovado em 26 de outubro de 2007)

\section{INTRODUÇÃO}

Solo-cimento é o material obtido pela interação íntima de solo, cimento Portland e água. Segundo Enteiche (1963), citado por Mercado (1990) e Grande (2003), trata-se de um processo físico-químico de estabilização e reorientação das partículas sólidas do solo com a deposição de substâncias cimentantes nos contatos intergranulares, alterando, portanto, a quantidade relativa de cada uma das três fases (sólida, líquida e gasosa) que constituem o solo.

\footnotetext{
${ }^{1}$ Engenheiro Agrônomo - Departamento de Agronomia - Universidade Estadual de Mato Grosso do Sul/UEMS - Unidade Universitária de Cassilândia Rodovia MS 306, Km 6.4 - Zona Rural - 79540-000 - pantaneiromemo@hotmail.com

2Engenheiro Agrícola, Doutor - Professor Adjunto - Faculdade de Ciências Agrárias - Universidade Federal da Grande Dourados/UFGD - Rodovia Dourados/Itahum, Km 12 - Cx. P. 533 - 79804-970 - Dourados, MS - gbiscaro@ufgd.edu.br

${ }^{3}$ Engenheiro Agrônomo, Doutorando, Professor Assistente - Departamento de Agricultura - Universidade Estadual Paulista/UNESP - Avenida Brasil, 56 Centro - 15385-000 - Ilha Solteira, SP - limanegro@uems.br

${ }^{4}$ Engenheira Agrônoma, Mestranda - Departamento de Engenharia Rural/DER - Faculdade de Ciências Agronômicas - Universidade Estadual Paulista/ UNESP - Rua José Barbosa de Barros, 1780 - Fazenda Lageado - Cx. P. 237 - 18610-307 - Botucatu, SP - alessandraloirinha@hotmail.com

${ }^{5}$ Engenheiro Agrônomo, Doutor, Professor Adjunto - Divisão de Pós-Graduação - Universidade Estadual de Mato Grosso do Sul/UEMS - Unidade Universitária de Cassilândia - Rodovia MS 306, Km 6.4 - Zona Rural - 79540-000 - Icarvalh@uems.br

${ }^{6}$ Graduanda - Universidade Estadual de Mato Grosso do Sul/UEMS - Unidade Universitária de Cassilândia - Rodovia MS 306, Km 6.4 - Zona Rural 79540-000 - stleal@hotmail.com
} 
A mistura de solo-cimento é submetida à compactação num teor de umidade ótimo para obtenção de máxima densidade, de modo a formar um material estruturalmente resistente e durável, utilizado na forma de tijolos, blocos e paredes monolíticas (LOPES \& FREIRE, 2003), apresentando boa resistência à compressão, bom índice de impermeabilidade e baixo índice de retração volumétrica (HABITAR, 2004)

Segundo a ABCP (1980), para se fazer a dosagem correta do solo-cimento é necessária a realização de uma seqüência preestabelecida de ensaios, sendo os resultados interpretados através de normas técnicas. $\mathrm{O}$ resultado de um estudo de dosagem seria a fixação de três quesitos básicos, a saber: o teor de cimento a ser adicionado no solo, a umidade a ser incorporada na mistura e a massa específica desejada. Os solos mais arenosos são os que se estabilizam com menores quantidades de cimento, porém é necessária a presença de argila na sua composição, visando dar à mistura, quando umedecida e compactada, coesão suficiente para a imediata retirada das formas (ABCP, 1985).

Atualmente, diversas pesquisas estão sendo realizadas envolvendo estruturas e materiais feitos com solo-cimento. Moraes et al. (2002) pesquisaram a resistência à compressão simples da mistura solo-cimento plástico, em função da idade de cura. Os resultados mostraram que houve aumento da resistência em função da idade, sendo que os ganhos consideráveis de resistência foram para períodos superiores aos 28 dias.

O uso de tijolos de solo-cimento produzidos por meio de prensas manuais apresenta vantagens em relação ao sistema convencional, entre as quais estão controle de perdas, disponibilidade de abastecimento, baixo custo, durabilidade e segurança estrutural, economia de transporte, quando produzido no próprio local da obra, e baixa agressividade ao meio ambiente, pois dispensa a queima (GRANDE, 2003). A eficácia da estabilização estrutural dos tijolos prensados de terra crua, com ou sem aditivos, é avaliada, comumente, por meio de testes físicomecânicos destrutivos como: ensaios de resistência à compressão simples, capacidade de absorção de água e durabilidade (GORDON et al., 1997; REN \& KAGI, 1995; WALKER, 1995; WEBB, 1992).

Ferreira \& Freire (2003) estudaram a combinação de métodos destrutivos e não-destrutivos para a avaliação da eficiência da estabilização do solo e da qualidade técnica de tijolos prensados de terra crua tratada com cimento, cal e silicato de sódio. Os teores de cimento e cal foram $0 \%$, $6 \%$ e $10 \%$, e a dosagem de silicato de sódio foi de $4 \%$ em relação ao peso seco da mistura solo-aditivo. Após a moldagem, os tijolos foram submetidos à cura durante períodos de 7, 28, 56 e 90 dias. As propriedades físicomecânicas dos tijolos foram determinadas através de testes destrutivos (resistência à compressão simples) e nãodestrutivos (ensaio de ultra-som). Os resultados indicaram que as adições de $10 \%$ de cimento e $10 \%$ de cal, respectivamente para solos arenosos e argilosos, foram as que promoveram melhores resultados em termos de resistência à compressão simples.

No Brasil, a produção e a aplicação de solo-cimento ainda é mais expressiva em obras de pavimentação (mais de $90 \%$ das bases das rodovias do país são de solo-cimento compactado), reforços e melhorias de solos e, finalmente em barragens e contenções (GRANDE, 2003).

Com este trabalho procurou-se verificar a viabilidade da utilização do montículo do cupim, abundante nas propriedades da região do município de Cassilândia/MS, como matéria- prima na fabricação de tijolos de solo-cimento.

\section{MATERIAL E MÉTODOS}

O experimento foi conduzido de agosto a setembro de 2006, no galpão de equipamentos do Setor de Produção Agrícola da Fazenda Escola, pertencente à Universidade Estadual de Mato Grosso do Sul (UEMS), Unidade Universitária de Cassilândia (UUC). Todos os tijolos fabricados, com auxílio de uma prensa manual, foram do tipo maciço, tendo em média as seguintes dimensões: 23 $\mathrm{cm}$ de comprimento, $10,8 \mathrm{~cm}$ de largura e $5,8 \mathrm{~cm}$ de altura. $\mathrm{O}$ montículo do cupim Cornitermes cumulans (Kollar, 1832) e o NEOSSOLO QUARTZARÊNICO (EMBRAPA, 1999), utilizados no experimento, foram coletados na área da Fazenda Escola.

O critério utilizado para realizar a escolha do solo e sua mistura com cimento foi baseado nas instruções e recomendações básicas do "Guia de construções rurais à base de cimento. Fascículo 2: como usar os materiais" da Associação Brasileira de Cimento Portland (ABCP, [19-]) e na norma NBR 10832 (ABNT, 1992), que trata da fabricação de tijolo maciço de solo-cimento com utilização de prensa manual, e cuja principal recomendação é de que o solo a ser utilizado seja, predominantemente, arenoso.

A análise físico-química do NEOSSOLO QUARTZARÊNICO (EMBRAPA, 1999), apresentou as seguintes características: $\mathrm{pHCaCl}_{2}=4,6 ; \mathrm{P}=2,0 \mathrm{mg} \mathrm{dm}^{-3}$; $\mathrm{K}=1,6 \mathrm{mmol}_{\mathrm{c}} \mathrm{dm}^{3} ; \mathrm{Ca}^{2+}=6,0 \mathrm{mmol}_{\mathrm{c}} \mathrm{dm}^{-3} ; \mathrm{Mg}^{2+}=7,0 \mathrm{mmol}_{\mathrm{c}}$ $\mathrm{dm}^{-3} ; \mathrm{H}+\mathrm{Al}=25,0 \mathrm{mmol}_{\mathrm{c}} \mathrm{dm}^{-3} ; \mathrm{Al}=3,0 \mathrm{mmol}_{\mathrm{c}} \mathrm{dm}^{-3}$; M.O.= $10,0 \mathrm{mg} \mathrm{dm}^{-3} ; \mathrm{Cu}=0,6 \mathrm{mg} \mathrm{dm}^{-3} ; \mathrm{Fe}=12,0 \mathrm{mg} \mathrm{dm}^{-3} ; \mathrm{Mn}=8,9$ $\mathrm{mg} \mathrm{dm}{ }^{-3} ; \mathrm{Zn}=0,3 \mathrm{mg} \mathrm{dm}^{-3} ; \mathrm{B}=0,37 \mathrm{mg} \mathrm{dm}^{-3}$. Os seguintes resultados foram observados na análise granulométrica: areia $=877 \mathrm{~g} \mathrm{~kg}^{-1}$; silte $=20 \mathrm{~g} \mathrm{~kg}^{-1} \mathrm{e}$ argila $=103 \mathrm{~g} \mathrm{~kg}^{-1}$. 
Já o montículo do cupim foi escolhido, inteiramente ao acaso, o mais próximo do ponto de coleta do NEOSSOLO (que no caso foi a 12,60 metros) e que apresentasse volume suficiente para a fabricação do número de tijolos necessários para as avaliações, e misturado com o cimento de acordo com as mesmas instruções e recomendações do guia da $\mathrm{ABCP}([19-])$ e da norma NBR 10832 (ABNT, 1992). Os cupins nele residentes foram identificados como sendo da espécie Cornitermes cumulans (Kollar, 1832), cuja característica principal é depreciar a terra em função, no caso de área de pastagens, por restringir o número de unidade animal por hectare.

A análise físico-química de uma amostra do montículo apresentou as seguintes características: $\mathrm{pHCaCl}_{2}=4,1 ; \mathrm{P}=4,0 \mathrm{mg} \mathrm{dm}^{-3} ; \mathrm{K}=1,1 \mathrm{mmol}_{\mathrm{c}} \mathrm{dm}^{3} ; \mathrm{Ca}^{2+}=7,0$ $\mathrm{mmol}_{\mathrm{c}} \mathrm{dm}^{-3} ; \mathrm{Mg}^{2+}=6,0 \mathrm{mmol}_{\mathrm{c}} \mathrm{dm}^{-3} ; \mathrm{H}+\mathrm{Al}=42,0 \mathrm{mmol}_{\mathrm{c}} \mathrm{dm}$ 3; $\mathrm{Al}=8,0 \mathrm{mmol}_{\mathrm{c}} \mathrm{dm}^{-3} ; \mathrm{M} . \mathrm{O} .=23,0 \mathrm{mg} \mathrm{dm}^{-3} ; \mathrm{Cu}=1,1 \mathrm{mg} \mathrm{dm}^{\mathrm{c}}$ ${ }^{3} ; \mathrm{Fe}=65,0 \mathrm{mg} \mathrm{dm}^{-3} ; \mathrm{Mn}=17,7 \mathrm{mg} \mathrm{dm}^{-3} ; \mathrm{Zn}=0,9 \mathrm{mg} \mathrm{dm}^{-3}$; $\mathrm{B}=0,37 \mathrm{mg} \mathrm{dm}^{-3}$. A análise granulométrica apresentou os seguintes resultados, que no triângulo textural caracteriza uma areia franca: areia $=810 \mathrm{~g} \mathrm{~kg}^{-1}$; silte $=39 \mathrm{~g} \mathrm{~kg}^{-1} \mathrm{e}$ argila $=$ $151 \mathrm{~g} \mathrm{~kg}^{-1}$.

No decorrer da pesquisa utilizou-se apenas um tipo de cimento Portland CPII F-32, da marca CAUÊ. A escolha do tipo de cimento foi determinada pela sua disponibilidade na região de Cassilândia/MS. Esse cimento, segundo o fabricante, supera os valores mínimos normatizados pela NBR 11578, referentes a cimentos portland compostos. O Quadro 1 apresenta as resistências mecânicas à compressão do CPII F-32, em MPa.

Em geral, o traço de referência para a fabricação de tijolos de solo cimento é o 1:10, sendo uma parte de cimento e dez partes de solo, como informa o Guia da Associação Brasileira de Cimento Portland. Adotou-se, neste trabalho, o traço 1:8, que é mais rico em cimento, e correspondeu utilização de uma parte de cimento para cada oito partes da matéria-prima utilizada (solo ou montículo do cupim), baseado em Grande (2003), que estudou a fabricação de tijolos modulares de solo-cimento, por prensagem manual, com e sem adição de matéria-prima sílica ativa, e que adotou um traço de referência de 1:10 e variações para análise de um traço rico em cimento (1:7) e outro pobre $(1: 13)$.

Antes de ser misturado com o cimento Portland CPII F-32, o NEOSSOLO passou por um processo de separação de eventuais restos orgânicos e quaisquer outros detritos existentes, e de uniformização da granulometria, através da utilização de uma peneira $\mathrm{n}^{\circ} .4$ $(4,8 \mathrm{~mm})$, de acordo com as recomendações da norma NBR 10832 (ABNT, 1992). Já o montículo do cupim foi primeiro triturado manualmente, sobre uma superfície revestida por uma lona plástica, e posteriormente submetido ao mesmo processo de separação e uniformização da granulometria, requerido pela norma da $\mathrm{ABNT}$.

Estando as duas matérias-primas preparadas, realizou-se a adição do cimento no traço de 1:8, e de água, até que se atingisse a consistência recomendada no guia da ABCP ([19- ]). Neste momento foi retirada uma amostra de cada mistura, que foi encaminhada para o laboratório de solos da UUC/UEMS, onde foi determinada a umidade média das amostras de $11 \%$, pelo método gravimétrico.

Depois de confeccionados, os tijolos foram submetidos ao processo de cura, e foram armazenados em local protegido do sol e do vento e molhados diariamente, de acordo com o período préestabelecido para cada tratamento. Encerrado esse processo, eles permaneceram armazenados durante 180 dias.

O experimento foi montado em DIC - Delineamento Inteiramente Casualizado - em esquema fatorial $2 \times 2$, sendo analisados dois cofatores, sendo o primeiro a matéria-prima base (montículo do cupim ou NEOSSOLO QUARTZARÊMICO) e o segundo a idade de cura (07 dias ou 28 dias). Para o principal fator avaliado, que foi a resistência à compressão (em prensa hidráulica com precisão de 1,0 kgf), foram testados 04 (quatro) tratamentos com 09 (nove) repetições cada. A analise estatística (Teste de Tukey, a 5\% no software STATISTICA for Windows, subprograma ANOVA/MANOVA) foi realizada apenas para os dados de resistência à compressão. Realizaram-se também a avaliação da quantidade de água absorvida pelos

Quadro 1 - Resistências mecânicas a compressão (MPa) do cimento CPII F-32, da marca Cauê.

\begin{tabular}{|l|c|c|c|c|}
\hline \multicolumn{5}{|c|}{ Resistências Mecânicas a Compressão (MPa) } \\
\hline Idades & 01 dia & 03 dias & 07 dias & 28 dias \\
\hline Norma NBR 11578 & - & $>10,0$ & $>20,0$ & $>32,0$ \\
\hline Cauê CPII F-32 & 11,0 & 26,0 & 31,2 & 39,0 \\
\hline
\end{tabular}

Fonte: Cimpasso Cimentos (2006). 
tijolos, as medidas das dimensões (utilizando régua de precisão em milímetros) e aferição das massas dos mesmos (balança digital, com precisão de 1,0 gramas).

Os ensaios físicos e mecânicos obedeceram às prescrições da norma da Associação Brasileira de Normas Técnicas NBR-8492 (ABNT, 1982) denominada "Tijolo maciço de solo-cimento: determinação da resistência à compressão e da absorção de água: método de ensaio" e da norma NBR-8491 (ABNT, 1984) denominada "Tijolo maciço de solo-cimento: especificação". Para a determinação da carga de ruptura (a qual foram submetidos os corpos de prova) utilizou-se um equipamento denominado prensa universal.

Os corpos de prova foram preparados seguindo a seguinte rotina: dividiram-se os tijolos ao meio, perpendicularmente à sua maior direção; as duas metades obtidas foram superpostas, através de suas faces lisas; essas faces foram ligadas por uma fina camada de cimento. Após o endurecimento, as amostras foram colocadas em um tanque com água, durante 15 minutos, para que absorvessem uma pequena quantidade de água e não a retirassem da pasta de cimento. Uma semana após a realização das fases anteriores, foi feito o capeamento dos corpos de prova, com uma camada de gesso. Só após essa preparação, os tijolos foram submetidos ao ensaio de carga de ruptura.

\section{RESULTADOS E DISCUSSÕES}

Os resultados das análises físicas apresentaram diferenças nas proporções das frações granulométricas do NEOSSOLO, em relação às do montículo do cupim, apesar de serem ambos os materiais coletados na mesma área, bastante próximos entre si (12,60 metros). Observase uma diferença na proporção das frações granulométricas de argila $(<0,002 \mathrm{~mm})$ e silte $(0,05$ a $0,002 \mathrm{~mm})$ e diminuição das frações areia $(2,0$ a $0,05 \mathrm{~mm})$ do montículo do cupim, em comparação com neossolo. Isso pode sugerir que os cupins podem estar buscando argila e silte em profundidade e concentrando-as nos montículos, ou se tratar apenas de uma variação espacial do solo, no local.

Os resultados das análises químicas mostram também diferenças nas características químicas de ambos os materiais. Entre as alterações, as mais pronunciadas foram o aumento nos teores de matéria orgânica (M.O), alumínio $(\mathrm{Al})$, fósforo $(\mathrm{P})$, cobre $(\mathrm{Cu})$, manganês $(\mathrm{Mn})$ e ferro $(\mathrm{Fe})$. Segundo Moreira \& Siqueira (2002), os organismos que habitam o solo são responsáveis direta ou indiretamente por processos bioquímicos diversos que controlam as transformações dos elementos químicos e as transferências de energia no sistema solo-planta-atmosfera. Dentro desse contexto, as alterações observadas podem estar vinculadas às atividades bioquímicas dos cupins, que modificaram as características químicas originais do solo. Dessa maneira, o aumento nos teores de Fe solúvel constatado na análise do montículo do cupim em relação à do NEOSSOLO, por exemplo, poderia ser explicado pela transformação desse elemento através das reações de oxi-redução e solubilização do elemento, conforme previsto em Siqueira (1993), que ainda argumenta que alguns processos bioquímicos, que ocorrem no solo, como a produção de metabólitos diversos (ácidos orgânicos), agem como substâncias solubilizantes quelantes e complexantes.

Por utilizar-se uma prensa manual para a fabricação dos tijolos, que pode causar possíveis variações no peso final dos mesmos, realizaram-se as aferições das massas de todos os tijolos analisados nesse experimento, em balança digital, com precisão 1,0 gr (Quadro 2 ).

A porcentagem de desvio-padrão, para os tijolos dos tratamentos T1, T3 e T4, ficou abaixo de $2,5 \%$, portanto dentro da faixa de aceitação; no entanto, os tijolos do tratamento T2 ficaram acima de 2,5\%, não atendendo plenamente à faixa de interesse. Tal problema ficou visível

Quadro 2 - Valores médios e desvio-padrão das massas dos tijolos dos tratamentos T1, T2, T3 e T4. Cassilândia/MS, 2006.

\begin{tabular}{|c|c|c|}
\hline \multirow{2}{*}{ Tratamento } & Peso Médio dos Tijolos & Desvio Padrão \\
\cline { 2 - 3 } & gr & 1,8 \\
\hline T1 & 2369,0 & 4,4 \\
\hline T2 & 2291,2 & 2,1 \\
\hline T3 & 2407,8 & 1,8 \\
\hline T4 & 2463,3 & \\
\hline Peso médio total & 2382,83 & \\
\hline
\end{tabular}

Ciênc. agrotec., Lavras, v. 32, n. 2, p. 553-560, mar./abr., 2008 
nos tijolos, que apresentavam defeitos no rebaixo central do tijolo, com perda pequena de material, possivelmente proveniente da lubrificação insuficiente da prensa no processo de prensagem dos tijolos, fato esse que acarreta defeitos nos mesmos. Porém esse é um problema que pode ser corrigido facilmente com a lubrificação adequada, e que não interferiu na resistência à compressão dos mesmos.

Os valores das cargas de ruptura foram obtidos para os tijolos, em ensaios realizados com a prensa hidráulica, com precisão 1,0 kgf. Com os valores da carga de ruptura se obtém a resistência à compressão, obtendose os resultados médios, apresentados no Quadro 3.

O tratamento T3 (idade de cura de sete dias e utilizando o montículo do cupim como matéria-prima) foi o que apresentou menor resistência à compressão, e o único a se diferenciar dos demais. Um dos fatores determinantes, em relação ao aumento da resistência mecânica de tijolos de solo-cimento, é o teor de cimento. No caso desse experimento, esse fator não exerceu nenhuma influência, pois utilizou-se apenas um único traço, para todos os tratamentos. Segundo Neves (1988), que estudou o uso de solo-cimento em componentes construtivos, a resistência à compressão desse tipo de mistura deve ser igual ou maior que 1,0 MPa, o que ocorreu em todos os tratamentos propostos nesse experimento.

Com exceção do tratamento T3, os demais tratamentos aqui propostos apresentaram valores de resistência maiores que 1,5 MPa. Milani \& Freire (2006), estudando as características físicas e mecânicas da mistura de solo, cimento e casca de arroz, consideraram 1,5 MPa o valor mínimo necessário para que a mistura solo-cimentocasca fosse aceitável, em termos de resistência mecânica, como elemento construtivo.

Verifica-se no Quadro 3 que o valor médio das resistências à compressão, em todos os tratamentos, foi maior à medida que se aumentaram as idades de cura, sendo que esse aumento foi de $46,1 \%$ nos tratamentos que utilizaram o montículo do cupim e de $5,8 \%$ nos que utilizaram o NEOSSOLO como matéria-prima.

Como pode ser observado na Figura 1, para a idade de cura de 07 (sete) dias, os tijolos que utilizaram como matériaprima o montículo do cupim (T3), apresentam o valor de resistência à compressão 34,8\% menor do que a dos tijolos que utilizaram o NEOSSOLO QUARTZARÊNICO (T1). Porém, aos 28 dias de cura, a resistência à compressão dos tijolos que utilizaram montículo do cupim (T4) foi 2,4\% maior do que a dos tijolos que utilizaram o acima referido solo (T2).

Todos os tratamentos tijolos apresentaram bons valores de resistência à compressão para a idade de 28 dias, estando dentro das faixas indicadas pela norma NBR-8492 (ABNT, 1982) denominada "Tijolo maciço de solo-cimento: determinação da resistência à compressão e da absorção de água. Método de ensaio", vindo a confirmar o que foi observado por Moraes et al. (2002), que é o aumento da resistência em função da idade, com ganhos consideráveis de resistência para períodos superiores a 28 dias.

Esse aumento na resistência com o aumento da idade de cura, observado em todos os tratamentos, deve-se em parte ao processo progressivo de hidratação do cimento, que confere maior resistência aos tijolos.

Um fator importante a ser salientado é que os resultados foram obtidos em condições de armazenamento diferentes de condições de laboratório, onde a cura dos tijolos é controlada em câmara úmida. Buscou-se nesse experimento aproximar-se, ao máximo das condições de armazenamento de canteiros de obra, que apesar de protegidos do sol e do vento, estavam expostos ao ar. A resistência à compressão tende ser menor por causa da perda de água do material por evaporação.

Os valores da absorção de água (AA) foram obtidos de acordo com a NBR-8492 (ABNT, 1982) e são apresentados no Quadro 4.

Quadro 3 - Resistência a compressão dos tijolos dos tratamentos T1 a T4. Cassilândia/MS, 2006.

\begin{tabular}{|c|c|c|c|c|}
\hline \multirow{2}{*}{ Tratamento } & Matéria prima & Idade de cura & $\begin{array}{c}\text { Resistência à } \\
\text { compressão }\end{array}$ & $\begin{array}{c}\text { Ganho de } \\
\text { Resistência }\end{array}$ \\
\cline { 3 - 5 } & & dias & $\mathrm{MPa}$ & 5,8 \\
\hline T1 & Neossolo quartzarêmico & 07 & $1,55 \mathrm{a}$ & 5,8 \\
\hline T2 & Neossolo quartzarêmico & 28 & $1,64 \mathrm{a}$ & 46,1 \\
\hline T3 & Montículo do cupim & 07 & $1,15 \mathrm{~b}$ & 46,1 \\
\hline T4 & Montículo do cupim & 28 & $1,68 \mathrm{a}$ & 18,78 \\
\hline F & & & & \\
\hline
\end{tabular}

Médias seguidas de letras iguais não diferem significativamente pelo teste de Tukey 0,05 . 


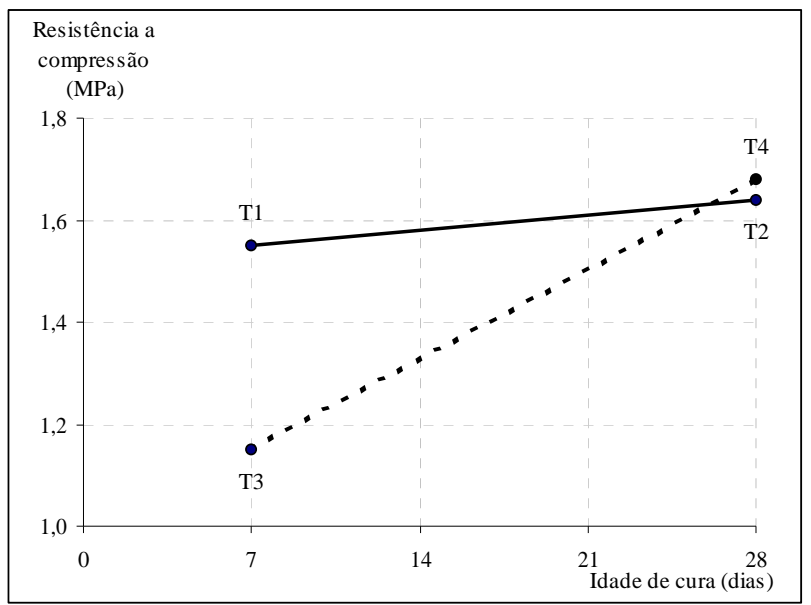

Figura 1 - Aumento da resistência à compressão (MPa), em função da idade de cura (dias). Cassilândia/MS, 2006.

Quadro 4 - Porcentagem de absorção de água em cada tratamento. Cassilândia/MS, 2006.

\begin{tabular}{|c|c|c|c|c|}
\hline \multirow{2}{*}{ Tratamento } & $\begin{array}{c}\text { Massa Seca do } \\
\text { Tijolo }\end{array}$ & $\begin{array}{c}\text { Massa Úmida do } \\
\text { Tijolo* }\end{array}$ & $\begin{array}{l}\text { Absorção de } \\
\text { Água }\end{array}$ & $\begin{array}{c}\text { Variação da Absorção de } \\
\text { Água }\end{array}$ \\
\hline & \multicolumn{2}{|c|}{ 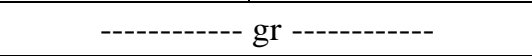 } & \multicolumn{2}{|c|}{-- } \\
\hline \multirow{3}{*}{$\mathrm{T} 1$} & 2232,1 & 2593,2 & \multirow{3}{*}{14,01} & \multirow{6}{*}{$+0,64$} \\
\hline & 2150,5 & 2528,8 & & \\
\hline & 2341,7 & 2697,5 & & \\
\hline \multirow{3}{*}{$\mathrm{T} 2$} & 2248,0 & 2635,3 & \multirow{3}{*}{14,10} & \\
\hline & 2313,7 & 2677,2 & & \\
\hline & 2260,3 & 2632,3 & & \\
\hline \multirow{3}{*}{$\mathrm{T} 3$} & 2396,9 & 2767,8 & \multirow{3}{*}{13,77} & \multirow{6}{*}{$-11,76$} \\
\hline & 2294,0 & 2680,1 & & \\
\hline & 2317,1 & 2679,8 & & \\
\hline \multirow{3}{*}{$\mathrm{T} 4$} & 2307,2 & 2643,8 & \multirow{3}{*}{12,32} & \\
\hline & 2572,4 & 2910,9 & & \\
\hline & 2350,7 & 2691,8 & & \\
\hline
\end{tabular}

*após 24h de imersão em água.

Observa-se que os valores de absorção obtidos tanto nos tijolos que utilizaram o NEOSSOLO quanto nos que utilizaram o montículo do cupim, estão dentro dos limites definidos pela NBR-8492 (ABNT, 1982).

Nos tijolos fabricados com o NEOSSOLO, com o aumento da idade de cura houve um incremento de $0,64 \%$ da absorção de água. Nos que utilizaram o montículo do cupim, ocorreu uma diminuição de 11,76\% (Figura 2). Portanto, esses últimos apresentaram resultados mais satisfatórios, pois a diminuição da absorção de água com a idade de cura, normalmente corresponde a um maior aumento da resistência à compressão. As maiores quantidades de argila e silte presentes no montículo do cupim, quando comparada as do NEOSSOLO, provavelmente conferiram uma maior plasticidade à mistura com o cimento.

Os tratamentos T1 e T2 apresentaram um aumento na resistência à compressão de 5,8\% e um aumento na absorção de água de $0,64 \%$. Já os tratamentos T3 e T4 apresentaram um aumento de $46,1 \%$ na resistência à 
compressão e uma diminuição de $11,76 \%$ na absorção de água. Conclui-se que a maior evolução da resistência mecânica dos tijolos de solo-cimento deu-se em função da diminuição da absorção de água dos mesmos, com a evolução da idade de cura de 07 para 28 dias.

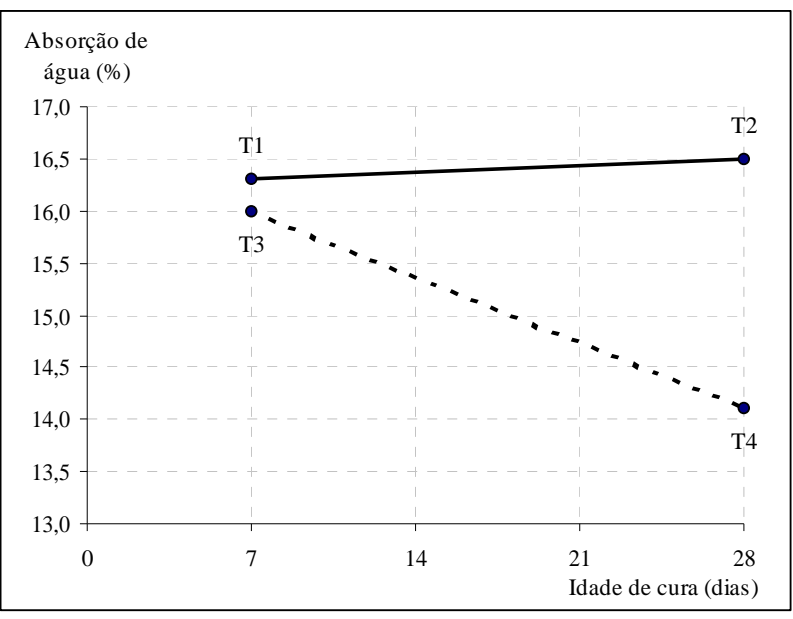

Figura 2 - Aumento da absorção de água (\%), em função da idade de cura (dias). Cassilândia/MS, 2006.

\section{CONCLUSÕES}

A resistência à compressão dos tijolos foi maior com o aumento das idades de cura. O tratamento T4 (idade de cura de 28 dias e utilização do montículo do cupim como matéria- prima) apresentou o maior valor de resistência à compressão, não diferindo estatisticamente dos tratamentos T2 (idade de cura de 28 dias e utilização NEOSSOLO QUARTZARÊNICO como matéria-prima) e T1 (idade de cura de 07 dias e utilização NEOSSOLO QUARTZARÊNICO como matéria-prima), tornando viável a utilização do montículo do cupim como matéria-prima, em substituição ao solo, na fabricação de tijolos de solocimento.

Os tijolos fabricados com o montículo do cupim Cornitermes cumulans (Kollar, 1832) apresentam diminuição da absorção de água com o aumento da idade de cura, ao contrário dos que utilizaram o NEOSSOLO. A diminuição da absorção com a idade, normalmente corresponde a um maior aumento da resistência à compressão.

\section{REFERÊNCIAS BIBLIOGRÁFICAS}

ASSOCIAÇÃO BRASILEIRA DE CIMENTO PORTLAND. Guia de construções rurais a base de cimento: fascículo 2: como usar os materiais. São Paulo, [19-]. 54 p.
ASSOCIAÇÃO BRASILEIRA DE CIMENTO PORTLAND. Dosagem das misturas de solo-cimento: normas de dosagem e métodos de ensaio. São Paulo, 1980.

ASSOCIAÇÃO BRASILEIRA DE CIMENTO PORTLAND. Fabricação de tijolos de solo-cimento com a utilização de prensas manuais. São Paulo, 1985. 8 p. BT-111.

ASSOCIAÇÃO BRASILEIRA DE NORMAS TÉCNICAS. NBR 10832: fabricação de tijolo maciço de solo-cimento com utilização de prensa manual. Rio de Janeiro, 1992. 8 p.

ASSOCIAÇÃO BRASILEIRA DE NORMAS TÉCNICAS. NBR 8491: tijolo maciço de solo-cimento: especificação. Rio de Janeiro, 1984.

ASSOCIAÇÃO BRASILEIRA DE NORMAS TÉCNICAS. NBR 8492: tijolo maciço de solo-cimento: determinação da resistência à compressão e da absorção de água: método de ensaio. Rio de Janeiro, 1982.

CIMPASSO CIMENTOS. Desempenho do cimento CPIIF-32. Disponível em: <http://www.cimpasso.com.br/ cpiif32.php\#>. Acesso em: 24 abr. 2006.

EMPRESA BRASILEIRA DE PESQUISA AGROPECUÁRIA. Centro Nacional de Pesquisa de Solos. Sistema brasileiro de classificação de solos. Brasília, DF, 1999. $412 \mathrm{p}$.

FERREIRA, R. C.; FREIRE, W. J. Eficiência da estabilização do solo e qualidade técnica de tijolos prensados de terra crua tratada com aditivos químicos, avaliadas pela combinação de testes destrutivos e não-destrutivos. In: CONGRESSO BRASILEIRO DE ENGENHARIA AGRÍCOLA, CONBEA, 32., 2003, Goiânia, GO. Anais... Goiânia: CONBEA, 2003.

GORDON, J. N.; PINNOCK, W. R.; MOORE, M. M. A preliminary investigation of strentth development in Jamaican red mud composites. Cement and Concrete Composites, [S.1.], v. 18, p. 371-379, 1997.

GRANDE, F. M. Fabricação de tijolos modulares de solocimento por prensagem manual com e sem adição de sílica ativa. 2003. 165 f. Dissertação (Mestrado) - Universidade de São Paulo, São Carlos, 2003.

HABITAR. Tijolos de solo-cimento. Disponível em: <http:/ /www.arq.ufmg.br/habitar/sis4.html>. Acesso em: 9 maio 2004. 
LOPES, W. G. R.; FREIRE, W. J. Análise comparativa de dois métodos usados para avaliar a aderência de taliscas de bambu encravadas em solo-cimento. In: CONGRESSO BRASILEIRODEENGENHARIAAGRÍCOLA-CONBEA, 32., 2003, Goiânia, GO. Anais... Goiânia: CONBEA, 2003.

MERCADO, M. C. Solo-cimento: alguns aspectos referentes a sua produção e utilização em estudo de caso. 1990. Dissertação (Mestrado) - Universidade de São Paulo, São Paulo, 1990.

MILANI, A. P. S.; FREIRE, W. J. Características físicas e mecânicas de misturas de solo, cimento e casca de arroz. Engenharia Agrícola, Jaboticabal, v. 26, n. 1, p. 1-10, jan./ abr. 2006.

MORAES, A. S.; SEGANTINI, A. A. S.; CARVALHO, D. Resistência à compressão do solo-cimento plástico. In: CONGRESSO BRASILEIRO DE ENGENHARIA AGRÍCOLA, CONBEA, 31., 2002, Salvador, BA. Anais... Salvador: CONBEA, 2002.
NEVES, C. M. M. Desempenho de paredes: procedimento adotado para paredes monolíticas de solocimento. In: SIMPÓSIO DE DESEMPENHO DE MATERIAIS E COMPONENTES DE CONSTRUÇÃO CIVIL, 1., 1988, Florianópolis. Anais... Florianópolis: [s.n.], 1988. p. 58-64.

REN, K. B.; KAGI, D. A. Upgrading the durability of mud bricks by impregnation. Building and Environmental, [S.l.], v. 30, n. 3, p. 433-440, 1995.

SIQUEIRA, J. O. Biologia do solo. Lavras: ESAL/FAEPE, 1993. $230 \mathrm{p}$.

WALKER, P. J. Strength, durability and shrinkage characteristics of cement stabilized soil blocks. Cement \& Concrete Composites, [S.1.], v. 17, p. 301-310, 1995.

WEBB, D. J. T. Lime stabilized soil blocks for third world housing. In: HILL, N.; HOLMES, S.; MATHER, D. Lime and other alternative cements. London: Intermediate Technology, 1992. p. 246-257. 